\title{
ESTADO Y MERCADO EN LA GLOBALIZACIÓN: LA REFORMULACIÓN DE LAS RELACIONES ENTRE POLÍTICA Y ECONOMÍA ${ }^{1}$
}

\author{
Carlos M. Vilas \\ Instituto Nacional de la \\ Administración Pública de la República Argentina
}

\begin{abstract}
RESUMO
Este artigo discute alguns dos principais aspectos das relações entre Estado e mercado no contexto da globalização econômica. Após uma apresentação sumária das modalidades de articulação entre Estadonação e capitalismo no passado, ressaltamos o impacto dos processos de globalização sobre a organização e as funções do Estado sob uma perspectiva dupla: a transformação das capacidades estatais como efeito das crescentes interconexões e interdependências dos atores e a funcionalidade de certas decisões adotadas pelo Estado para dar maior impulso à globalização.
\end{abstract}

PALAVRAS-CHAVE: Estado; desenvolvimento; globalização; mercado.

\section{INTRODUCCIÓN}

La tensión entre la delimitación territorial del Estado-nación y la dinámica transterritorial del capital recorre toda la historia moderna. El Estadonación es una forma particular de dominación política con explícito referente territorial. De acuerdo a una conceptualización de raigambre weberiana, el Estado moderno es la unidad suprema de decisión respecto de la población de un territorio. Desde perspectivas tan variadas como el iusnaturalismo y el marxismo, esta unidad suprema de decisión es cualificada por finalidades específicas: la búsqueda del bien o la felicidad común, la dominación de clase, la grandeza nacional, u otras. Persiste en todas las conceptualizaciones, sin embargo, una inequívoca referencia a la demarcación territorial del poder estatal. Por el contrario, desde sus orígenes en las ciudades renacentistas del norte de Italia, el capitalismo desplegó un extraordinario dinamismo transterritorial que, después de más de cinco siglos, lo ha llevado a convertirse en el régimen de organización económica y social dominante en el globo. Las fronteras territoriales, esenciales para la existencia y funcionamiento del Estado-nación, son contingencias que el capital respeta o no en función de su propia dinámica expansiva ${ }^{2}$.

Los escenarios actuales de la globalización plantean con datos originales una cuestión que no es completamente nueva. Interrogarnos sobre el Estado en la globalización significa, ante todo, indagar el modo particular de expresarse y procesarse en el capitalismo contemporáneo aquella tensión. Una de las características más observadas en nuestros días es la extraordinaria interconexión de procesos e instituciones en escala mundial. Esa interconexión introduce modificaciones profundas en la organización y la capacidad de gestión de los Estados.

\footnotetext{
2 En esta exposición las expresiones "Estado-nación" y "Estado moderno" son empleadas como sinónimos. La "nación” del Estado refiere a la demarcación territorial de la pretensión imperativa estatal y no tiene referentes étnico-culturales necesarios. Vid Smith (1986); Hobsbawm (1990).
}

1 Este es un documento preliminar; forma parte de un trabajo más extenso, en preparación, sobre el tema del título. Una versión anterior se presentó en el $I$ Congreso Interoceánico de Estudios Latinoamericanos (Universidad Nacional de Cuyo, Mendoza, 10-12 marzo 1999). Las opiniones vertidas son personales del autor y no involucran al INAP. 
A partir de esta constatación, una literatura abundante, de calidad desigual, afirma la supuesta desaparición del Estado. La creciente integración de la economía como efecto combinado de los avances en la tecnología de las comunicaciones, el transporte y los medios masivos, y la extraordinaria liquidez internacional, cobrarían sus más notorias víctimas en los Estados. En un mundo sin fronteras, el Estado-nación, típico de la historia del capitalismo desde sus orígenes hace 500 años, estaría desapareciendo a manos del post-moderno "príncipe electrónico", o bien transformándose en una herramienta de museo, interesante pero inservible y, de hecho, contraproducente. La globalización habría hecho posible, finalmente, la desaparición del Estado anunciada en el siglo pasado por el socialismo marxista y por el anarquismo ${ }^{3}$.

Sin embargo, el número de Estados ha crecido de manera extraordinaria en los años recientes. En 1991 la organización de las Naciones Unidas contaba con 143 miembros; hoy existen más de 200. ¿Cómo compatibilizar aquellas hipótesis con estas cifras? Puede argumentarse que existen Estados y estados - como bien ilustra la desigualdad de derechos institucionalizada en el Consejo de Seguridad de la propia ONU - en cuyo caso el tema en discusión es el de las capacidades y la eficacia de los Estados y de su viabilidad como formas efectivas de organización política. En tal caso, la desaparición o la redundancia afectaría mucho más a algunos que a otros, pero no podría sostenerse como una proposición general. Muchos de los estados "nuevos" surgidos tras la débâcle soviética y el desmembramiento de la federación yugoslava deben tanto a la eclosión de ideologías fundamentalistas de tipo racial o religioso, como a la dinámica de la política exterior de algunos estados tradicionalmente influyentes en determinadas regiones. En varios de estos casos funciones tradicionalmente vinculadas al ejercicio de la soberanía estatal son desempeñadas por otros Estados o por corporaciones de negocios. Cuestiones de política de poder de larga data serían en es-

3 Ohmae (1990; 1997) presenta la versión más difundida, aunque no necesariamente la más sólida, de esta tesis. Vid en el mismo sentido O’Brien (1992) y Horsman \& Marshall (1994). Según Castells (1997, p. 243ss) el Estado pierde poder pero no influencia - distinción que le parece "esencial" (p. 244), pero que no desarrolla. La denominación de "príncipe electrónico" pertenece a Octavio Ianni (1998). tas situaciones mucho más relevantes para explicar el surgimiento y efectividad de estos Estados, que la dinámica del capitalismo en escala mundial ${ }^{4}$.

Generalmente se piensa en la globalización económica como un factor que restringe la eficacia y los alcances de las decisiones adoptadas desde el Estado. Ello es así y constituye el tema central de esta exposición. Sin embargo la globalización económica no es la única fuerza de cuestionamiento de la autonomía decisoria del Estado, ni todo en la globalización actúa en este sentido.

A lo largo del siglo XX, y sobre todo después de 1945, el derecho internacional y la familia de organismos vinculada a la Organización de las Naciones Unidas generaron un sistema normativo que ha acotado la libertad decisoria de los Estados en muchos aspectos. Más aún: hoy se acepta que no sólo los Estados, sino también los individuos y algunos grupos "privados", son sujetos activos del derecho internacional (por ejemplo, la Declaración Universal de Derechos de 1948, la Convención Internacional contra el Ejercicio de la Tortura, o el Convenio 169 de la OIT), y se admite de manera progresiva que individuos y grupos pueden demandar ante tribunales internacionales incluso a "sus" Estados. La institucionalización de los derechos humanos permite someter a proceso judicial por crímenes contra la humanidad a delincuentes perdonados por las autoridades de sus propios países. Estos desarrollos normativos contribuyen a institucionalizar lo que en otra ocasión denominé "globalización de la idea de justicia” (VILAS, 1994a). La eficacia de esta normatividad no es aún completa y los instrumentos para dotarla de plena imperatividad todavía son precarios. Muchos de los actores institucionales que celebran el acotamiento de la soberanía estatal en materia económica y financiera, y contribuyen a la misma, se cobijan en una versión absoluta de las potestades estatales en otras materias, como ha quedado demostrado en el caso Pinochet. Menciono aquí el tema como una ilustración de la pluralidad de elementos que gravitan en la identificación de los márgenes efectivos de autonomía decisoria de los Estados.

\footnotetext{
4 Sobre el involucramiento directo de firmas militares de Estados Unidos en los conflictos bélicos en Bosnia y Croacia vid Lynch (1997), Graham (1997); US Neres and World Report (1997); Arbucki (1997); en general, vid Sheppard (1998).
} 
Al mismo tiempo, algunos de los ingredientes que han contribuído a la mayor globalización de la economía han ayudado a mejorar algunas capacidades de la gestión estatal. La incorporación de las innovaciones de la informática a la gestión pública amplió la recolección, sistematización y análisis de datos de las agencias gubernamentales y dio al Estado mayor capacidad de control y disciplinamiento sobre la población. Los mismos desarrollos técnicos que favorecen la casi instantánea movilidad del capital abren posibilidades de mayor autonomía a los actores sociales y, también, de mayor fiscalización a las autoridades. Finalmente, los estados han desempeñado y siguen desempeñando un papel estratégico en el rediseño de las respectivas economías y en su articulación a los escenarios internacionales.

La exposición que sigue tiene pretensiones modestas; indaga solamente algunos aspectos de la articulación entre el Estado y el capitalismo en nuestros días. En la primera parte se explicitan de manera muy breve las nociones básicas de autonomía y soberanía del Estado, que muchas veces resultan indiferenciadas. Se presenta a continuación un resumen de las modalidades de la articulación entre Estado-nación y capitalismo en momentos anteriores al actual. En distintas épocas existieron formas y estilos variados de articulación entre el Estado y la expansión del capital; la diferenciación entre gobiernos y empresas de negocios ha variado a lo largo del tiempo, incluyendo momentos de simbiosis entre unos y otros. Contextualizar historicamente el asunto mejora la comprensión de sus manifestaciones presentes. La tercera sección presta atención a los aspectos de la globalización contemporánea de mayor pertinencia para nuestro asunto. Sin perjuicio del impulso adquirido por la proyección global del capital, los mercados nacionales conservan mucha importancia en los procesos de acumulación, sobre todo en las economías más desarrolladas. Sin perjuicio de la extraordinaria aceleración de los flujos internacionales de capital, la idea de un mercado global no tiene asidero en la realidad de los hechos. En la cuarta parte se presta atención al impacto de estos procesos en la organización y las funciones del Estado desde una doble perspectiva: la transformación de las capacidades estatales como efecto de las crecientes interconexiones e interdependencias de los actores y la funcionalidad de ciertas decisiones adoptadas por el Estado para dar mayor impulso a la glo- balización. Finalmente, en la quinta parte se ensaya una lectura más conceptual de los argumentos planteados en las secciones anteriores.

\section{AUTONOMÍA Y SOBERANÍA}

Desde los inicios de la modernidad con la consolidación del capitalismo como sistema tendencialmente dominante de producción y de organización económica, la territorialidad del Estado tiene como delimitación la nación entendida ésta en sentido jurídico-político más que étnico o cultural. La supremacía del poder estatal, vale decir su soberanía; su legitimidad efectiva (la hegemonía) y su capacidad para garantizar un margen de autonomía respecto de otros estados (la independencia) son el resultado de múltiples factores históricos, estructurales, políticos y culturales, y del sistema internacional de poder. La soberanía del Estado, se expresa en dos aspectos principales: el monopolio de la coacción física legítima, y la emisión de moneda de curso forzoso.

Cuando se hace referencia al Estado hay que tener presente que en él se sintetizan dos dimensiones básicas. Una se refiere al Estado como expresión institucional de relaciones de poder y de principios de legitimación; es decir la dimensión tipicamente política del Estado. La segunda dimensión se refiere a las capacidades de gestión: lo que usualmente se denomina administración pública y, más recientemente, políticas públicas. Es ésta una dimensión derivada de la anterior, en la que el Estado define y ejecuta cursos de acción, y extrae y asigna recursos en función de objetivos referibles al núcleo de su politicidad.

La discusión acerca del impacto de la globalización en el Estado se refiere principalmente a esta segunda dimensión, pero lleva implícitas referencias a la primera. La etapa presente de la globalización es el resultado de cambios profundos en las relaciones de poder entre actores. Como efecto de ellos, el Estado ha visto modificadas su organización, sus funciones y el sentido de su acción. Hay nuevas relaciones de poder en el mundo, que condicionan de qué cosas puede o debe hacerse cargo legítimamente el Estado, y de qué manera, y qué cosas o modalidades de acción le están vedadas (VILAS, 1997a). Como siempre ocurre, cambios en las relaciones de poder se traducen en nuevos diseños institucionales y en modificaciones en la gestión pública. 
En esta presentación se hablará más de la autonomía decisoria del Estado que de su soberanía. Autonomía implica siempre algún tipo de negociación entre actores. Mayor o menor autonomía estatal respecto de ciertos actores (empresas, sindicatos, otros Estados, organismos multilaterales) significa mayor o menor capacidad del Estado para definir objetivos y estrategias de acción, movilizar recursos, ejecutar políticas, reducir las restricciones que emergen de los otros actores y de los escenarios que en conjunto configuran. Que se trate de actores "internos" ("nacionales") o transnacionales, no es en sí relevante. Por su parte, soberanía significa capacidad de imposición de las decisiones estatales por encima de cualquier otro actor dentro del territorio de ese Estado. Lo que usualmente se considera deterioro o crisis de la soberanía es, las más de las veces, retracción de la autonomía estatal. Los ejemplos que se dan usualmente para abonar la hipótesis de la erosión de la soberanía - las condicionalidades de los organismos financieros multilaterales, la homogenización transterritorial de las políticas económicas, y otros - son, más exactamente, muestras de una delegación de facultades decisorias en virtud del ejercicio de un poder soberano. Este modo de ejercerse la soberanía puede ser juzgado atinado o desacertado, pero esa es harina de otro costal. La privatización de una empresa o la suscripción de un crédito externo pueden ser el resultado de presiones y negociaciones en las que el Estado posee mayor o menor autonomía. Pero la decisión de privatizar, o de endeudarse, implica un acto de soberanía.

Lo anterior no significa negar que existan decisiones adoptadas por un Estado que deterioren el ejercicio efectivo de la soberanía. En Argentina, por ejemplo, el régimen de convertibilidad adoptado por ley del Congreso Nacional es una decisión política que pone fin a esa dimensión de la soberanía que se refiere a la capacidad del Estado de imponer curso forzoso a la moneda nacional, en escenarios en los que una parte grande de la población repudiaba la moneda oficial y la sustituía por monedas extranjeras que suscitaban mayor confianza. Este caso muestra también que no toda retracción de las capacidades soberanas de un Estado es resultado de la globalización. En este ejemplo, la decisión fue una respuesta al desafío inflacionario que el país venía arrastrando desde más de tres décadas, incluyendo periodos breves de hiperinflación, en los más variados escenarios económico-financieros internacionales ${ }^{5}$.

Corresponde precisar desde el inicio, por lo tanto, qué entendemos por autonomía del Estado respecto de los actores de la economía en sentido amplio. Se recordará que en la década de 1960 el tema suscitó algunos debates interesantes en la teoría política, que no es necesario reproducir aquí - entre otros motivos porque tenía como referente a un tipo de Estado capitalista e incluso a un tipo de capitalismo, que han cambiado mucho desde entonces. Para los fines de esta presentación, se entiende por autonomía del Estado la capacidad de las autoridades públicas para definir objetivos y fijar metas acordes a ellos, seleccionar y utilizar instrumentos eficaces y eficientes, movilizar recursos en función de los objetivos y las metas, y mantener bajo control las restricciones dentro de las cuales operan las políticas públicas - incluyendo el comportamiento de otros actores. Esta autonomía nunca es absoluta y ciertamente no lo ha sido en ninguno de los Estados latinoamericanos. En el fondo, es una dimensión del tipo de relaciones que se generan entre el Estado, la sociedad y la actividad económica, y de los escenarios regionales y mundiales en los que la relación se desenvuelve. En la medida en que el Estado es institucionalización de relaciones de poder, los alcances efectivos y el sentido real de la autonomía estatal derivan de las relaciones de poder así institucionalizadas.

\section{ESTADO Y CAPITAL}

La dinámica expansiva del capitalismo ha conocido momentos de aceleración y de desaceleración. Cada uno de ellos presenta articulaciones particulares entre el poder político y el

\footnotetext{
5 Conviene recordar que la desnacionalización de la moneda es una recomendación planteada desde hace tiempo por algunos teóricos neoliberales, como una condición para acelerar la fluidez internacional de los mercados, y no como un resultado de ella (cf. por ejemplo Hayek, 1978). La proliferación de organismos internacionales (como los de la familia de la ONU y más recientemente la Organización Mundial del Comercio) y de tratados y convenios en materia de protección ambiental, tráfico de estupefacientes, etcétera, es presentada como una prueba de acotamiento de la soberanía de los estados miembros. Se omite la circunstancia de que todos los estados exigen, como condición previa de validez de las disposiciones respectivas, la previa ratificación de los convenios por las autoridades nacio-nales (usualmente el poder legislativo).
} 
poder económico, entre los gobiernos y las empresas, entre el Estado y el mercado.

El siglo XVI fue uno de extraordinaria expansión territorial del capitalismo europeo hacia América, Africa y Oriente, junto con el desarrollo inicial de los mercados nacionales y la progresiva constitución de los Estados modernos. En el siglo siguiente el mercantilismo fue la política económica del Estado absolutista que permitió la primera fase de consolidación de la burguesía. Los gastos militares expandieron los ingresos de los ciudadanos del Estado que los efectuaba; esa expansión aumentó la capacidad financiera estatal por la vía de los ingresos tributarios. El gasto militar del Estado absolutista constituyó un estímulo estratégico a la expansión del capital; la necesidad de administrarlo racionalmente dio origen a las modernas burocracias ${ }^{6}$. La paz de Westfalia (1648) institucionalizó el sistema internacional basado en el equilibrio (relativo) de poder entre los Estados-nación y en la observancia de las fronteras recíprocas. La expansión transterritorial del capital combinó el establecimiento de colonias de población en América del Norte, Africa, Asia y el Pacífico, el desarrollo de la esclavitud capitalista, y el nacionalismo económico (BLACKBURN, 1998).

Con diferentes enfoques y proyecciones Carlos Marx y Max Weber llamaron la atención sobre la alianza entre el capitalismo emergente y el Estado moderno en formación. Esa misma relación se advierte en la expansión global del capitalismo. El principal vehículo de la globalización del capital fue la capacidad de los Estados europeos para realizar operaciones de ultramar por medio de fuerzas militares y navales aptas para encarar viajes de gran alcance. La difusión del poder europeo se llevó a cabo principalmente a través de las campañas marítimas que eran a un mismo tiempo militares y comerciales. Hacia el siglo XVII el éxito militar y el éxito económico estaban vinculados estrechamente. En los siglos siguientes el poder militar y naval de Gran Bretaña consolidó la centralidad de Londres en el mundo del comercio y las finanzas. El Estado moderno devino la forma suprema de Estado porque logró organizar con éxito la extracción y movilización

6 Con cierta ironía, un autor denomina "keynesianismo militar" a este aspecto de la política estatal: Arrighi (1994, p. 38). de recursos económicos para financiar la guerra, para impulsar la expansión capitalista, y para legitimarse a sí mismo (HELD, 1997, p. 83ss).

El sistema interestatal europeo se desarrolló en el contexto de dos procesos fundamentales: la afirmación de la soberanía estatal y la difusión global de las nuevas relaciones económicas a través de los mecanismos capitalistas. En este desarrollo confluyeron los intereses de la emergente clase capitalista de las ciudades y los de los gobernantes. La primera buscaba eliminar los obstáculos a la expansión de las relaciones de mercado, que derivaban de los compromisos comerciales impuestos por las redes de poder urbanas y rurales - cofradías, gremios, nobleza, terratenientes. Los segundos estaban empeñados en centralizar el poder político, la administración fiscal y la conducción de la guerra, desmontando las bases de poder de la nobleza, la iglesia y los cuerpos estamentales.

Tras la revolución industrial, la superioridad económica y técnica y el mayor desarrollo de sus estructuras estatales permitieron a Inglaterra imponer a la periferia una política de libre comercio. Esa política estuvo amparada por el poder de fuego de la armada real, en beneficio de los comerciantes e inversionistas británicos en ultramar. La abolición de las leyes de pobres y de granos consolidaron el poder del capital sobre los trabajadores, y de los industriales respecto de los agricultores. El capitalismo europeo ingresó en una etapa de desarrollo "en profundidad" que le habría de permitir la ocupación progresiva de la totalidad del espacio delimitado por las fronteras estatales. La institucionalización del orden político conservador en el Congreso de Viena (1815) generó un equilibrio inter-estatal fundamental para la expansión doméstica del capitalismo. Durante el medio siglo siguiente la "ocupación" total de los mercados nacionales tuvo tanta relevancia como la extroversión hacia el resto del mundo.

Nuevos desarrollos científicos y técnicos aplicados a la producción habrían de crear una de las condiciones para pasar otra vez a una expansión predominantemente transterritorial. El desarrollo de nuevas aleaciones de acero permitió construir barcos de mayor tonelaje, más livianos y veloces, ampliando el transporte de personas y de mercancías y el comercio internacional; alrededor de 45 millones de europeos migraron hacia el continente americano entre 1870 y 1920. La energía eléctrica compitió exitosamente con el vapor; se 
avanzó sustancialmente en nuevas técnicas y procedimientos de conservación de alimentos; el telégrafo y el ferrocarril acortaron tiempos y espacios; nuevas técnicas de organización del trabajo industrial habrían de dar impulso a la producción en gran escala. Este conjunto de transformaciones permitió ampliar y profundizar la cobertura geográfica nacional e internacional del capital.

El Tratado de Berlín de 1871 dio estatus institucional al reparto del mundo entre las principales potencias europeas. La exportación de capitales, técnicas y poblaciones desde Europa al resto del mundo contó con el auxilio del poder de fuego de los Estados y con la operatoria de sus instituciones financieras. Después de la crisis de 1873 este proceso se amplió y adquirió un nuevo dinamismo. Las inversiones de capital metropolitano diseñaron la infraestructura económica en las regiones de ultramar. La canalización de las inversiones productivas a través del sistema bancario y de los mercados de bonos desarrolló en escala exponencial al capital financiero. El sistema alcanzó sus niveles de mayor desarrollo en la década de 1920; la especulación financiera en escala transnacional llegó a niveles sólo comparables con los de nuestros días ${ }^{7}$.

La quiebra del sistema en 1929-30 puso fin al período de globalización acelerada. Desde entonces el mundo ingresó en un nuevo momento de "desarrollo en profundidad" y estabilización de la dinámica global del capital que habría de extenderse hasta la década de 1970. Los flujos comerciales y financieros internacionales se desaceleraron. La reorientación fue resultado del descalabro internacional. La necesidad de salir de la crisis en que culminó la anterior etapa de globalización acelerada, mucho más que la ideología, aconsejó reorientar las respectivas economías hacia adentro de sus fronteras. El socialismo soviético, el nacionalismo económico nazi y fascista, la teoría económica de Keynes, el

\footnotetext{
7 El mejor análisis de las especulación financiera como base de la economía capitalista pertenece al heterodoxo sociólogo alemán Georg Simmel. Su Filosofía del dinero, publicada originalmente en 1900, tiene como referente inmediato los escenarios de extraordinaria volatilidad de la época (SIMMEL, 1978). Galbraith (1990) presenta un recuento agudo, de más extensa cobertura, de estos procesos.
}

New Deal estadounidense, la socialdemocracia europea, estimularon esta reorientación y dotaron al Estado de nuevas funciones en la economía y en la sociedad.

Concluida la segunda guerra mundial la guerra fría introdujo una nueva división política, militar e ideológica en el mundo. Parte importante de Europa Central, China y otros países de Asia decidieron apartarse del sistema capitalista, y varios nuevos Estados del "tercer mundo" intentaron escoger una "tercera vía" de desarrollo. La geopolítica conspiró contra la dinámica globalizadora del capitalismo. Este período alcanzó su momento de mayor auge en las tres décadas posteriores a la segunda guerra mundial . En los años setentas la pérdida de dinamismo era evidente. Tras la crisis de los ochentas hemos ingresado en una fase de expansión transterritorial particularmente vertiginosa. El colapso del bloque soviético contribuyó adicionalmente a derribar las barreras a este nuevo despliegue.

Una economía predominantemente autocentrada no es incompatible con cierta orientación hacia mercados externos, pero en tal caso la apertura canaliza flujos y valores comparativamente reducidos, y el esquema global de acumulación tiene al mercado interno como referente y horizonte principal. En consecuencia, en este período las políticas del capitalismo definieron como interlocutores privilegiados del Estado a las empresas que producían para los mercados internos y a los trabajadores organizados en sindicatos. La orientación del conjunto de la actividad económica hacia el mercado nacional creó condiciones para mejorar los salarios y los niveles de vida de los trabajadores y los sectores medios. Esto es lo que se conoció en Europa como Estado de bienestar. Es éste un Estado con un conjunto amplio de instituciones estratégicas para la acumulación de capital y para la reproducción ampliada de la fuerza de trabajo, en un marco regulatorio complejo que permitió la gestión dinámica de las demandas y los conflictos sociales.

La viabilidad fiscal del Estado de bienestar está condicionada por la capacidad del sector público para captar y movilizar los recursos necesarios para su financiamiento, y al mismo tiempo garantizar una adecuada tasa de ganancia al capital. Se requiere, como mínimo, una presión tributaria que aporte recursos para el financiamiento del bienestar, sin que esa carga genere desestímulos 
a la inversión de capital, y el auspicio y promoción de sistemas de innovación que garanticen la elevación sostenida de la productividad de las empresas y de la eficiencia de la gestión pública. Llega un momento sin embargo en que este equilibrio solo puede ser mantenido con costos crecientes - reducción tendencial de la tasa de acumulación por caída de la rentabilidad del capital, deterioro de la productividad, pérdida de mercados externos, inflación, caída tendencial de los niveles de bienestar, crecimiento del desempleo, entre otros. Los costos también son de índole política: por ejemplo, erosión de la base electoral de los partidos que apoyan este tipo de equilibrios, pérdida de legitimidad del Estado de bienestar.

En estos escenarios crecen tanto la oposición empresarial, que critica la pérdida de productividad y de competitividad, como la oposición sindical y social, que se agravia por el deterioro de las condiciones de vida. Aparece en consecuencia el fantasma de la inestabilidad política y la ingobernabilidad. Vale decir, el peligro de que el Estado deje de ser capaz de procesar con eficacia las demandas cruzadas que le formulan los actores del mercado y de la sociedad, y de adaptarse a los nuevos escenarios internacionales. En Europa occidental y en Estados Unidos este período de crisis se extendió desde finales de la década de 1960 hasta principios de la de 1980. Los factores endógenos que se acaba de mencionar se vieron agravados por el impacto de la guerra de Vietnam en Estados Unidos y por el alza de los precios del petróleo en Europa. En América Latina, donde el Estado de bienestar nunca fue una realidad plena, el esquema culminó su crisis en 1982. Estos acontecimientos diseñaron el escenario y las condiciones para el relanzamiento de la globalización capitalista.

El muy acelerado desarrollo industrial de algunos países de Asia a partir de la década de 1950 y hasta muy recientemente - sobre todo en comparación con la evolución seguida en el mismo lapso por la mayoría de las economías de América Latina y el Caribe - muestra una similar articulación entre Estado y mercado y, más en general, entre política y economía. La conjunción de las necesidades estratégicas de Estados Unidos en esa parte del mundo en el inicio de la guerra fría y las orientaciones desarrollistas de las élites políticas locales dotadas de fuerte coherencia interna, definieron las condiciones de lanzamiento y ejecución del más exitoso de los modelos de desarrollo capitalista del último medio siglo. Similarmente, el cambio en el escenario político regional gravitó pesadamente en la suerte reciente de esas economías ${ }^{8}$. Algunos observadores han señalado la formación de un "complejo Wall Street-Tesoro Federal de Estados Unidos-FMI" para el rediseño de la economía en general y en particular para la mayor inserción de las grandes corporaciones occidentales en Asia a partir de la crisis en esa parte del mundo y del rediseño de los escenarios políticos regionales (WADE \& VENEROSO, 1998a, 1998b). Las transformaciones en los escenarios posteriores a la guerra fría y en particular la centralidad creciente de los choques y conflictos comerciales entre las economías más desarrolladas está induciendo modificaciones importantes en las modalidades de intervención política estatal en función de intereses y objetivos económicos y comerciales nacionales que recuerdan mucho los escenarios tradicionales previos a la década de $1930^{9}$.

Una perspectiva de largo plazo indica por lo tanto que los períodos de transterritorialización del capital son la culminación de un ciclo largo cuyo primer momento es dinamizado por el predominio de la acumulación "hacia adentro". Es esta etapa

\footnotetext{
8 La literatura sobre el "milagro asiático" es vasta pero desigual. En lo que toca a la conjugación de política y mercado, y a la gravitación de actores políticos externos, vid. por ejemplo Johnson (1982), Harris (1986), Kolko (1988), Wade (1990), Evans (1989, 1995), Aseniero (1996).

9 En julio de 1995 Los Angeles Times informó que el presidente Clinton ordenó a la CIA hacer del espionaje económico y comercial su "más alta prioridad", reflejando la importancia acordada por su gobierno a los asuntos económicos y comerciales en la política exterior. Los nuevos blancos de la inteligencia son Japón, Alemania, Francia y otros miembros de la Unión Europea. De acuerdo a Los Angeles Times la CIA proporcionó información a la Casa Blanca durante el conflicto con Japón por el ingreso de autos japoneses al mercado estadounidense, informando sobre las posiciones secretas de los rivales económicos de EEUU al respecto. Para ello intervino clandestinamente conversaciones entre funcionarios y empresarios japoneses, informando luego al representante comercial Mickey Kantor. Esta no fue una operación aislada; Ron Brown, en su calidad de Secretario de Comercio, reconoció antes del accidente en el que falleció la utilidad de los servicios de la CIA para promover los intereses comerciales de su país. Vid Vilas (1997b).
} 
la que genera las condiciones para el relanzamiento internacional de las inversiones. En tal sentido, el presente período de aceleración de la circulación transnacional del capital no constituye el comienzo de una nueva etapa, mucho menos el inicio de una nueva era, sino al contrario la culminación del ciclo de acumulación que se abrió hace casi setenta años.

El paso al momento de la expansión transterritorial del capital siempre está ligado a la “financierización" amplia de la economía. El predomino del capital financiero respecto del capital productivo no es, como frecuentemente se cree, una característica particular de los tiempos que vivimos. Al contrario, es la condición de posibilidad de la ampliación y la aceleración de la circulación internacional del capital. A su vez, la mayor velocidad y proyecciones de la movilidad geográfica del capital financiero ha sido favorecida, en todos los tiempos, por cambios importantes en la tecnología informática. En la etapa anterior de expansión global del capitalismo (1870s-1920s) ese salto estuvo protagonizado por el telégrafo, el teléfono y la radiofonía. Hoy, son los desarrollos y aplicaciones en materia de informática, microelectrónica y multimedios.

Cada una de estas etapas en el desarrollo del capitalismo muestra articulaciones diferenciadas entre el Estado y el mercado. En las tres primeras décadas de nuestro siglo existió un consenso amplio en la teoría económica y en la política económica de los gobiernos, que redujo el papel del Estado al de un mero garante de la lógica del mercado. La crisis de 1929-30 destruyó ese consenso. Se generó, al contrario, la convicción de que el Estado debía desarrollar un papel activo en la recomposición de los equilibrios perdidos. El grado de intervención postulado para el Estado fue variable, pero la idea de que el mercado autoregulado es el asignador más eficiente de los recursos fue abandonada ante la evidencia del descalabro, las necesidades de la economía de guerra, las exigencias de la posterior reconstrucción, y las demandas de las clases populares. En conjunto, estos elementos condujeron a que la producción y distribución de gran número de bienes y servicios saliera de la esfera de la producción y circulación mercantil. Hoy, las contradicciones que se acumularon en el Estado de bienestar, el modo en que se emergió de la crisis de los años ochentas, y una nueva correlación de fuerzas políticas, vuelve a desplazar el péndulo de los enfoques económicos y de política hacia el polo del Estado gendarme del mercado. La persistente crisis económica y el vertiginoso deterioro social en Rusia tras el derrumbe del régimen soviético testimonian el impacto del quiebre de las estructuras estatales en las perspectivas de desarrollo del capitalismo. Rusia ha pasado de un exceso absoluto de Estado a un déficit absoluto de Estado.

\section{LA GLOBALIZACIÓN DEL CAPITAL, HOY}

La etapa actual de globalización, con su extraordinaria volatilidad, no surgió de improviso o desde la nada. Los desarrollos tecnológicos, las transformaciones en las relaciones de poder en escala internacional y la evolución económica del capitalismo fueron sentando progresivamente las bases de la etapa presente. La literatura de las décadas de 1960 y 1970 sobre la internacionalización del capital, el redespliegue industrial o las empresas multinacionales, enfocó los momentos anteriores y los procesos que condujeron a los escenarios de hoy (VILAS, 1994b).

Las transformaciones en la proyección internacional del capital se apoyaron, y al mismo tiempo estimularon, modificaciones de gran alcance en la organización y el despliegue espacial de las empresas. Predominan actualmente esquemas de descentralización en redes y por proyectos. La competencia se desenvuelve en torno a la calidad, la diversificación, y la reducción del tiempo de entrega de los productos. Se pone énfasis en la flexibilidad de los procesos productivos y de las relaciones laborales. Con el debilitamiento progresivo del grado de territorialidad de las actividades económicas y de la importancia del emplazamiento territorial de los recursos, la localización de las diversas operaciones de una empresa se convierte en una variable de elección para sus instancias de dirección. La mayor movilidad del capital permite que las conducciones empresarias elijan y sustituyan territorios sin pérdidas de eficiencia, competitividad o rentablidad. Esta libertad no es uniforme; varía de acuerdo a sectores y actividades, y entre países.

Las manifestaciones actuales de la globalización se apoyan en la apropiación desigual de los desarrollos científicos y técnicos en materia informática, transportes y comunicaciones, en el marco de una extraordinaria liquidez internacional. Estos elementos aceleran de manera exponencial 
la circulación internacional de los factores, pero de manera desigual. Es globalización del capital más que de la fuerza de trabajo; es mayor en lo referente al capital financiero que al capital productivo, y en la aplicación de técnicas e instrumentos más que en la generación de nuevo conocimiento.

Abandonado a su propia dinámica, el proceso de globalización es fuertemente diferenciador: ahonda las desigualdades entre países ricos y países pobres y preserva o agrava las disparidades dentro de cada sociedad. Entre 1980 y 1994 el grupo de países que el Banco Mundial considera más desarrollados incrementó su porción del producto mundial de $70 \%$ a $79 \%$; los países de nivel medio de desarrollo la redujeron de $23 \%$ a $16 \%$, y los países más pobres retrocedieron de siete a cinco porciento ${ }^{10}$. En este mismo período el PBI por habitante creció en todo el mundo, pero con ritmos extremadamente diferenciados. En consecuencia, mientras en el año 1980 el PBI promedio por habitante en el mundo desarrollado era más de once veces mayor al del promedio en el resto del globo y casi treinta y tres veces más alto que en los países más pobres, en 1994 se había disparado a más de veinte veces respecto del resto del mundo, y a más de sesenta y dos veces por encima del promedio en los países de ingreso bajo (VILAS, 1999, cuadros 2 y 3). Un mundo económicamente más globalizado no es, por lo tanto, un mundo más homogéneo.

La globalización debe ser enfocada como parte de un movimiento mayor que, por lo tanto, la trasciende: la vocación expansiva de la acumulación de capital. Afirmar que la cuestión central es el capital, no un momento determinado de su desarrollo (la globalización) significa poner énfasis en que el desarrollo actual de la globalización no significa una ruptura con todo lo anterior y el ingreso a una nueva era, sino un mo-

\footnotetext{
10 El Banco Mundial considera países de alto nivel de desarrollo a aquéllos con un PBI por habitante anual promedio de más de US\$ 9000,00 . En el grupo figuran todos los países de la OCDE (con excepción de México), Israel, Corea, los estados petroleros de Medio Oriente, entre otros. Todos los países de América Latina (con excepción de Haití, Honduras y Nicaragua) y los de Europa Central figuran entre los de "nivel medio" de desarrollo. Los países incluídos en el "nivel bajo" son aquéllos con un PBI medio anual por habitante inferior a 450 dólares anuales.
}

mento específico en ese proceso multisecular propio de la dinámica del capitalismo. Al mismo tiempo, este énfasis conlleva un riesgo: la referencia a lo general del capitalismo puede impedirnos percibir y analizar la multiplicidad de factores específicos o particulares de este momento singular ${ }^{11}$. Es necesario por lo tanto, tomar en cuenta lo particular junto con su pertenencia a una realidad más amplia: ver los árboles en el bosque al que constituyen.

Sin perjuicio de su aceleración reciente, la globalización dista aún de ser realmente global. El Banco Mundial advierte que la mitad de la población de los países en desarrollo está aún al margen del crecimiento de los flujos del comercio y de capital que se ha venido experimentando desde la década de 1980 (WORLD BANK, 1997, p. 12). El propio Ohmae reconoce que solamente los países que cuentan con un ingreso medio anual por habitante de más de diez mil dólares participan activamente de la misma - es decir, solamente 15\% de la población mundial (OHMAE, 1990).

La globalización muestra un desarrollo desigual también en lo que se refiere a sus dimensiones constitutivas. La "financierización" de la economía global ha adquirido niveles sin precedentes. Desde principios de la década de 1970 la volatilidad de las tasas de interés y de las divisas provocó el crecimiento vertiginoso de los contratos de futuro, con nuevas modalidades. En 1972 aparecieron los contratos sobre divisas, lanzados por el Chicago Mercantile Exchange, y en 1975 surgieron los contratos sobre tasas de interés, del Chicago Board of Trade. Desde la década de 1980 existen mercados similares en Londres, París, Frankfurt, Sidney, Tokio. Se estima que $95 \%$ de las operaciones de los mercados cambiarios, que en 1996 ascendían a 1.3 billón de dólares por día (alrededor de 400 billones en el año), consiste en movimientos de fondos que arbitran tasas de interés, tipos de cambio y expectativas de los mercados bursátiles. Alrededor de $80 \%$ de las transacciones en esos mercados da origen a

\footnotetext{
11 Un representante moderado del enfoque "rupturista" es Octavio Ianni: vid por ejemplo Ianni $(1992,1996)$. La posición opuesta puede verse, por ejemplo en Wood (1997) y Tabb (1997). A partir de 1995 se ha desarrollado en las páginas de Montbly Review un muy interesante debate entre la óptica "generalista" y la óptica "rupturista”.
} 
movimientos de entrada y salida en plazos no mayores de siete días, esto es, a un promedio de 50 movimientos al año. Por cada 100 dólares de inversión en activos fijos en todo el mundo, los préstamos alcanzaban a 6,2 dólares en 1964, y a más de 130 dólares a principios de la década de 1990. Si se compara con el comercio internacional, las relaciones son de 7,5 y 105 en esos mismos años, respectivamente (FERRER, 1997; DEFARGUES, 1997).

Esta es la parte más visible de la globalización, sobre todo por contraste con el período inmediatamente anterior, y la que es tenida en cuenta la mayor parte de la veces en que el tema es referido. Pero es solamente una parte. Las transformaciones indicadas no han eliminado todavía la importancia económica de los espacios nacionales para la acumulación. El valor del comercio mundial es apenas un tercio del valor de la producción mundial, lo cual indica que dos tercios del producto se realizan en los mercados nacionales respectivos. Además, la apertura externa de las economías es menor en los países más desarrollados que en los de menor desarrollo: 0,32 y 0,40 respectivamente (VILAS, 1999, cuadro 1). En los últimos cincuenta años el comercio creció más rápido que la producción: el PBI mundial aumentó a una tasa anual de $4 \%$ promedio entre 1945 y 1996, mientras el comercio internacional lo hizo al $6 \%$. De continuar la tendencia estas relaciones variarán en las próximas décadas. Entre tanto, el "mundo sin fronteras" sigue siendo, en buena medida, una hipótesis ${ }^{12}$.

Algo similar ocurre con las corporaciones transnacionales, sin dudas uno de los actores más dinámicos de la globalización. La participación de las filiales de esas corporaciones en el producto mundial ronda el 7\%. En los países industriales el producto de las filiales de sus corporaciones transnacionales equivale a $6 \%$ del producto nacional. Ello sin perjuicio de que, contrariamente a la imagen más difundida, existe también en estas

\footnotetext{
12 Los ejemplos favoritos de la hipótesis del "mundo sin fronteras" son los de las plataformas exportadoras del sudeste asiático: Singapur y Hong Kong sobre todo. Sin embargo, en el conjunto de economías del "Grupo de los 7” (Japón, Estados Unidos, Francia, Italia, Alemania, Reino Unido y Canadá), el comercio exterior representaba en promedio poco más de $26 \%$ del producto nacional en 1990, y menos de $25 \%$ en 1994.
}

grandes firmas una clara orientación regional, y una marcada diferenciación en materia de sistemas de innovación, criterios de inversión y gerenciamiento de recursos que expresa la gravitación de los respectivos países donde radica el centro de actividades de la firma ${ }^{13}$. Lo anterior no significa desconocer el enorme peso de las corporaciones transnacionales en la economía mundial, sobre todo con relación a las regiones menos desarrolladas, sino llamar la atención sobre la proporción correcta de las cosas. La imagen de las empresas transnacionales como actores todopoderosos de la globalización tiene que ver fundamentalmente con la situación de los mercados emergentes y los países periféricos; sobre esta cuestión se vuelve en la sección siguiente.

Este conjunto de factores explica la persistente concentración de las inversión extranjera y los flujos del comercio, en las áreas de mayor desarrollo. Más de $80 \%$ de la inversión extranjera directa, y $84 \%$ del comercio internacional, siguen siendo procesados entre las economías más desarrolladas de la OCDE. Es éste un fenómeno que se registra a lo largo del último medio siglo y que no tiene visos de modificarse (PINTO \& KÑAKAL, 1971; VILAS \& SILVA, 1976; BORGES, 1994; CEPAL, 1997). La persistencia de la concentración de la inversión extranjera directa en los países más desarrollados, con niveles altos de salarios y de impuestos, demuestra que salarios bajos y permisividad fiscal no son estímulos determinantes para el arribo de inversiones foráneas - contrariamente a lo que imagina la mayoría de los gobiernos latinoamericanos.

Aunque la caracterización de "firmas nacionales con operaciones internacionales" (HU, 1992) no puede generalizarse para todas las grandes corporaciones transnacionales, la existencia de la "corporación global" como el actor predominante en el escenario económico mundial es una exageración carente de sustento. En la

13 En 1995 el 75\% de las ventas de las grandes firmas alemanas en el sector manufacturero se realizaron en territorio alemán; los porcentajes para firmas de Gran Bretaña fueron $65 \%$, de $79 \%$ para las firmas de Estados Unidos. En 1993 el 97\% de la inversión de capital fijo de las firmas manufactureras de Japón se llevó a cabo. Vid por ejemplo Guillén Romo (1993, 1994), Borges (1994), Weiss (1997), Navarro (1997). 
mayor investigación sistemática llevada a cabo hasta ahora sobre este aspecto, Doremus y asociados concluyen que la "corporación global" es un mito. Encuentran, al contrario, una persistente influencia de las estructuras nacionales de los estados donde se basan las matrices de las principales empresas del mundo. Esas estructuras siguen dando cuenta de la sorprendente diversidad en el carácter de las principales operaciones encaradas por las firmas. De acuerdo a esto, las operaciones más importantes de las corporaciones transnacionales siguen variando sistemáticamente de acuerdo a diferencias nacionales. En particular, los sistemas de innovación tecnológica muestran grandes diferencias de estilo de acuerdo a patrones culturales, institucionales, históricos e idiosincráticos. Lo mismo debe decirse de las estrategias de endeudamiento de las empresas y de contratación de personal de nivel gerencial. La corporación global, liberada de sus alojamientos políticos y operando en un mercado crecientemente global, es un mito (DOREMUS et alii, 1998) ${ }^{14}$.

Las diferencias que se registran entre la rentabilidad del capital en los sectores de bienes transables (bienes cuya oferta local compite con la oferta internacional vía comercio exterior) y bienes no transables (bienes en los que la competencia externa es inexistente o marginal) ilustran adicionalmente la importancia de las fronteras y los espacios nacionales para la acumulación de capital. Las actividades referidas al segundo tipo de bienes (industria de la construcción, servicios de infraestructura, hotelería, rentas inmobiliarias urbanas y rurales, entre otras) presentan fuertes restricciones a la movilidad internacional y pueden desarrollarse en condiciones de protección natural por la reducida movilidad de sus productos, sin necesidad de políticas proteccionistas universalmente estigmatizadas. Una empresa aérea debe competir en materia de tarifas, calidad de servicios, etc. en el plano internacional, pero no en el plano doméstico, o bien en este plano la competencia es mucho menor. No existe un "precio internacional" de la energía eléctrica, o de los servicios de telecomunicación: las tarifas varían de país en país y no

\footnotetext{
14 Esta investigación identifica tres grandes sistemas de innovación: anglo-sajón, germano-europeo, y japonés. Vid en un sentido coincidente Weiss (1998).
}

son transables en el comercio internacional ${ }^{15}$. Algo similar debe decirse de la diversidad nacional de los mercados de dinero y la falta de convergencia del precio del capital, de los coeficientes de ahorro interno y de otras variables igualmente significativas (WEISS, 1997; WADE \& VENEROSO, 1998a). Es por demás llamativo que estas cuestiones no sean siquiera consideradas en la literatura de la "economía sin fronteras".

Se concluye por lo tanto que la globalización financiera y los avances en la transterritorialización se desarrollan junto con la persistencia de la importancia de los espacios económicos nacionales para el proceso global de acumulación. La integración de la economía mundial es mucho más intensa que en la etapa anterior, pero ello no ha significado hasta ahora una convergencia de los sistemas de acumulación de capital, de los estilos de desarrollo y de la calidad de vida, y es cuestionable que ocurra en el futuro próximo.

\section{ESTADO Y GLOBALIZACIÓN DEL CAPITAL}

Los procesos actuales de globalización de la economía plantean en términos particulares la cuestión de la articulación necesaria entre Estado y capital. ¿Qué papel juega el Estado en estos escenarios? Se ha visto en las secciones anteriores que la tesis del "fin del Estado", en los términos en que se plantea usualmente, carece de sustento en los hechos y en su desenvolvimiento previsible. Pero es innegable que el tipo de relaciones entre Estado y mercados, en los escenarios contemporáneos, plantea situaciones novedosas y obliga a una redefinición de las capacidades estatales y de los alcances de su gestión. El desarrollo vertiginoso de la globalización financiera, su gravitación sobre las otras dimensiones de la economía, y las nuevas modalidades de organización de las empresas están transformando la eficacia y los alcances de la gestión pública e impulsando cambios de gran alcance en la organización del

\footnotetext{
$\overline{15}$ Un ejemplo bastará para comprender la situación. La tarifa que el Correo Argentino cobra por una carta simple, con destino nacional, es de 75 centavos de dólar; esa misma carta, dentro de Estados Unidos, costaría 33 centavos de dólar. Remitida desde Buenos Aires a Nueva York la misma carta tiene un franqueo de 1,25 dólar, mientras que depositada en el correo estadounidense y remitida hacia Buenos Aires, tendría un franqueo de 60 centavos.
} 
Estado y en el sentido de su funcionamiento ${ }^{16}$. Además, la proliferación de acuerdos internacionales y la intensificación de los procesos de interconexión regional e interregional después de 1945, los desarrollos tecnológicos recientes y la aceleración de la circulación transnacional del capital, erosionaron la distinción entre asuntos externos e internos. Como resultado de todo esto, los márgenes de acción del Estado, y el arco de decisiones que puede adoptar por sí mismo, se han acotado de manera considerable.

Los desafíos de la globalización operan en escenarios de relaciones desiguales entre Estados. El escenario internacional es uno de profundas disparidades. Los Estados de mayor poder gravitan pesadamente a través de sus agencias gubernamentales en el diseño de las políticas de otros Estados. A través de sus embajadas, de la infantería de marina y de la AID el gobierno de Estados Unidos modeló hasta muy recientemente las estructuras y el funcionamiento de los Estados en gran parte del mundo, e impuso gobiernos dispuestos a ejecutar políticas determinadas. En estos y otros casos semejantes, la cuestión de la autonomía estatal se presenta con características que no son las de los Estados centrales, y es llamativo que estas diferencias no sean consideradas en la literatura predominante sobre el tema. Inciden también en el impacto de la globalización algunos factores adicionales: por ejemplo, la ubicación del Estado en la división internacional del trabajo, su posición con respecto al sistema jurídico internacional, su relación con las organizaciones internacionales más importantes. Las condiciones de adaptación a los procesos exógenos y el margen de maniobra frente a las relaciones de poder internacional son frágiles en Estados con economías fuertemente endeudadas, o con sociedades muy fragmentadas o polarizadas. Cuando se discute el impacto de los procesos económicos y financieros transfronterizos es importante por lo tanto no magnificar artificialmente las capacidades regulatorias del Estado en los estilos precedentes de desarrollo. Las capacidades del Estado no existen en abstracto sino que son una resultante de la articulación de estilos y estrategias de desarrollo impulsadas por actores concretos que apelan a la movilización tanto de recursos del mercado como a la imple-

$\overline{16}$ Vid un planteamiento general en Vilas (1997a). mentación de políticas públicas.

Es indudable, en este sentido, que el Estado desarrollista de inspiración keynesiana siente los embates de los escenarios actuales y de los actores que los hegemonizan ${ }^{17}$. En materia de objetivos, por ejemplo, aumenta el número y la importancia de los que dejan de ser opciones viables (por ejemplo, la garantía del pleno empleo o de un salario remunerador) y crece el costo de recurrir a políticas "inamistosas" a los mercados financieros y a los actores que los orientan (por ejemplo, nacionalizaciones y regulaciones). La autoridad monetaria pierde capacidad para fijar de manera autónoma metas cuantitativas. Se reduce también el número de instrumentos tradicionales en este enfoque, además de disminuir su eficacia. Priva una actitud opuesta a la propiedad estatal de activos; se reduce o desaparece el recurso a políticas de tarifas de servicios públicos para estimular el desarrollo de ciertas regiones. La desregulación de los sistemas financieros reduce la eficacia de la política monetaria. La autonomización institucional de los bancos centrales y la adopción de sistemas de cajas de conversión reducen los alcances y la eficacia de esa política y del manejo del tipo de cambio - en el límite, es el Estado emisor de la divisa adoptada como referente quien decide la política monetaria. Los mercados financieros tienen poca tolerancia a políticas nacionales de retraso cambiario (como se advirtió en la crisis mexicana de 1994-95, en la asiática de 1997-98, en la de Rusia en 1998, y en la más reciente de Brasil). El funcionamiento de los mercados financieros las veinticuatro horas del día permite la sustitución instantánea de monedas en las carteras de los inversionistas.

Decae también la capacidad estatal para movilizar recursos en función de los objetivos de política. Se adoptan políticas de permisividad tributaria hacia el gran capital como forma de mantener el ingreso de flujos externos; hay una notoria incapacidad de contención de la evasión fiscal. Los compromisos externos y los subsidios al capital absorben porciones importantes de los

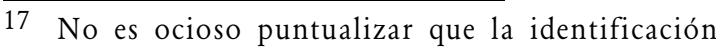
automática de la intervención estatal en los mercados con la macroeconomía de inspiración keynesiana es, al menos en América Latina, excesiva. En muchos casos se trató de tradicionales mecanismos de dominación patrimonialista y de rentismo.
} 
recursos fiscales. La disminución de los recursos movilizables reduce la capacidad para fijar objetivos y metas. Finalmente, aumentan las restricciones en número, en grado de complejidad y en importancia estratégica. El despliegue transterritorial y el crecimiento de los flujos comerciales y de inversión entre filiales o subsidiarias de una misma firma, o entre la matriz y aquéllas (aproximadamente dos quintos del comercio mundial y casi dos tercios de toda la inversión extranjera directa), regidos por sistemas de precios de transferencia - es decir, al margen de las relaciones de mercado - reduce la eficacia de la política fiscal. Al contrario, las firmas bajan riesgos en sus operaciones de cambio, evitan controles de precios y optimizan el plan tributario global. La interdependencia de las instituciones financieras, la inestabilidad de precios de los activos financieros, el desarrollo de nuevos productos y derivados que reducen la transparencia del sistema financiero por la complejidad de su contabilidad, y la vulnerabilidad del sistema de pagos interbancarios, reducen la capacidad institucional de prever el funcionamiento de los mecanismos de transmisión monetaria e incrementa el riesgo sistémico.

El gigantismo de muchos de los actores corporativos de la globalización acentúa la contracción de la capacidad de acción de los Estados en los países periféricos. Los activos conjuntos de las diez mayores corporaciones de Estados Unidos por volumen de ventas (General Motors, Ford Motor, Exxon, Wal-Mart Stores, General Electric, IBM, AT\&T, Mobil, Chrysler y Philip Morris, todas ellas con presencia en América Latina) sumaron en 1996 más de un trillón de dólares. Esta cantidad representa la cuarta parte del valor conjunto del PBI de las 56 economías que el Banco Mundial considera como de ingreso medio: catorce países con cerca de 400 millones de personas. La decisión de cualesquiera de estas empresas, o de otras similares a ellas, de cerrar una planta y transferir sus actividades de un país a otro en respuesta a políticas fiscales que considera inconvenientes para sus negocios, o por cualquier otro motivo, crea problemas serios al país afectado tanto en el terreno de la competencia económica como en el de la efectiva vigencia de las instituciones democráticas (REICH, 1998; VILAS, 1998) ${ }^{18}$. Esta situación ilustra la conti-

18 Esto es algo que se está viendo ahora mismo con par- nuidad, en los nuevos escenarios, de uno de los rasgos más tradicionales de la inserción latinoamericana a la economía mundial: el poder desproporcionado de algunas corporaciones (United Fruit, Standard Oil, Anaconda, Grace, Rosario Mining...) vis-à-vis los estados del mundo en desarrollo.

A esto deben agregarse los condicionamientos derivados de la relación subordinada de muchos Estados a organismos financieros multilaterales como el Fondo Monetario Internacional o el Banco Mundial. La vinculación a estos organismos es formalmente optativa, pero usualmente la alternativa a ella suele ser el caos económico y el quiebre del Estado. Los requisitos impuestos por el FMI o el Banco Mundial para el desembolso de fondos necesitados de manera desesperada por los Estados definen restricciones fuertes a las políticas de los gobiernos respectivos. Hasta hace pocos años estas restricciones se referían exclusivamente a las políticas económicas, pero con posterioridad se han ampliado a cuestiones de naturaleza más obviamente política: reforma de la legislación laboral, sistemas de marcas y patentes, organización del poder judicial, sistemas electorales, regímenes de prestación de servicios públicos etcétera ${ }^{19}$.

El cambio de los escenarios, el creciente poder de los actores de la economía globalizada y la red de condicionamientos institucionales contribuyen a la configuración de lo que Stephen Gill denominó "un nuevo constitucionalismo para un neoliberalismo disciplinario" (GILL, 1992, p. 157-196). El proyecto de Acuerdo Multilateral de Inversiones (AMI) representaría la culminación de este nuevo orden jurídico-económico supraestatal. El Acuerdo está en proceso de discusión por la OCDE desde 1995 y ha recibido el impulso de la Organización Mundial de Comercio. En caso de ser

ticular dramatismo en varios países del Caribe, donde las plantas de ensamble de filiales de firmas transnacionales están trasladándose a México para ampararse en el Tratado de Libre Comercio de América del Norte y gozar de preferencias en el mercado estadounidense. La gravedad de la situación se comprueba, entre otras cosas, en el énfasis con que los gobiernos afectados - a los que se sumaron los de Centroamérica - reclamaron al presidente William Clinton tomar cartas en el asunto, en la reunión de mandatarios en Barbados en abril 1997.

19 Vid un planteamiento general en World Bank (1997). Para una posición más extrema, Burski \& Edwards (1996). 
aprobado, el AMI se convertiría en la base normativa de un sistema político transnacional que institucionalizaría la subordinación del Estado a las grandes corporaciones (OCDE, 1998).

El AMI define como titulares exclusivos de los derechos que establece a las empresas, mientras que los gobiernos asumen todas las obligaciones; garantiza a los inversores el derecho a invertir en las condiciones de desregulación establecidas por el tratado, es decir sin restricción alguna; los gobiernos deben asegurar el pleno goce de este derecho. Se establece la indemnización a los inversionistas en caso de intervenciones gubernamentales que limiten su remesa de utilidades, libertad de operación, y similares, e incluso por acciones estatales que puedan ser consideradas como expropiación, incluso indirecta, de oportunidades de ganancia - y no sólo de activos. Los gobiernos quedan privados de la facultad de ejecutar políticas activas - por ejemplo, estimulando algunas líneas de producción o el desarrollo de ciertas regiones; concediendo créditos preferenciales; fijando medidas de protección al medio ambiente o a categorías específicas de trabajadores (mujeres, ancianos, discapacitados, veteranos de guerra...) etc. En el fondo, el AMI expropia a los Estados la política económica. En caso de litigio entre una empresa y un Estado, el diferendo deberá someterse incondicionalmente a arbitraje internacional. Es interesante que el AMI prevé el caso de un Estado demandando a otro, y de un inversionista demandando a un Estado, pero no la hipótesis de un Estado demandando a un inversionista (por ejemplo por incumplimiento de compromisos de inversión). Se permite la existencia de monopolios públicos o privados siempre que actúen de acuerdo a "consideraciones comerciales". Es decir, las empresas públicas deben adoptar criterios mercantiles, abandonando posibles objetivos promocionales o asistenciales. Se establece asimismo un mecanismo llamado de "desmantelamiento" por el cual las medidas gubernamentales no conformes con las disposiciones del AMI serán progresivamente eliminadas. Si es firmado, el tratado se convertirá en norma de referencia por la generalidad de sus cláusulas, y los tratados bilaterales o multilaterales ya firmados tendrían sólo validez subsidiaria. Sólo están previstas dos excepciones: las obligaciones asumidas por los Estados como firmantes de los estatutos del FMI, y los principios rectores de la OCDE.
El AMI es todavía un proyecto, pero ofrece un buen ejemplo de la intencionalidad de las corporaciones de negocios de imponer su búsqueda de ganancia como objetivo y finalidad suprema de la sociedad. Para tal fin se estima necesario restringir al máximo la autonomía del Estado vale decir, acotar la posibilidad de que el Estado asuma como referente de su actividad objetivos y horizontes distintos a la maximización de la ganancia del capital.

Esta matriz de tensiones y el retroceso de la eficacia decisoria autónoma del Estado no deberían interpretarse simplemente como el resultado de una imposición del capital contra la voluntad del Estado. Ver al Estado simplemente como una víctima de la globalización es observar sólo una parte de la cuestión. El Estado también ha probado ser un facilitador de la globalización, un agente particularmente estratégico para su mayor desarrollo. En América Latina y en otras regiones del mundo en desarrollo el Estado ha reforzado, por la vía de la desregulación y las privatizaciones en gran escala, la capacidad de decisión de los actores de la economía internacional. Orientados por nuevas correlaciones de poder que expresan la primacía de esos actores, los Estados compiten entre sí para ofrecer las mejores condiciones institucionales a las inversiones foráneas, circunstancia que es aprovechada por los inversores para elevar sus exigencias de seguridad - en particular, de libre egreso ${ }^{20}$. En el último tercio del siglo 19 el Estado dinamizó la consolidación institucional de los grupos primarioexportadores y su articulación a las líneas de punta del mercado internacional. Después de la crisis de 1929-30, en el marco de un nuevo escenario internacional, creó las condiciones para el ascenso de las élites industriales orientadas hacia el mercado interno, y más tarde promovió su asociación al redespliegue industrial de las economías más avanzadas. Hoy, en escenarios

20 Las crisis financieras y sus efectos depredadores resultan así un ingrediente del funcionamiento normal de estos esquemas. Es interesante señalar que el BID, en su balance de una década de reformas, se refiere a las crisis - incluyendo entre ellas explícitamente a la crisis mexicana de diciembre 1994 - como "mecanismos de corrección”, sin diferenciarla respecto de otros mecanismos de corrección, de carácter preventivo y de efecto mucho menos drástico (BID, 1997). 
externos diferentes, el Estado es el soporte institucional de los actores económicos que tratan de adecuarse a los nuevos términos del capitalismo internacional.

Este conjunto de situaciones explica que, después de un primer momento de fuerte énfasis en la necesidad de reducir la gestión estatal a un mínimo, y de presentar al estado como el principal obstáculo a la reestructuración económica en clave neoliberal, la literatura referida al ajuste macroeconómico y a la globalización, y las recomendaciones de los organismos multilaterales involucrados en estos procesos demandan hoy una más decidida gestión pública, sin la cual el ajuste no puede llevarse a cabo. En esta línea de razonamiento se reconoce el carácter estratégico de una gestión activa del Estado para la competitividad efectiva de los mercados; la necesidad de una reforma de la administración de justicia; el papel relevante de las políticas públicas en el acceso de los agentes económicos a información; el rol estratégico del Estado en la formación y capacitación de los recursos humanos; la necesidad de regulación pública del funcionamiento de algunos mercados, etcétera (WORLD BANK, 1997; BURSKI et alii, 1998) ${ }^{21}$.

Un número creciente de funcionarios y economistas insisten en la necesidad de un papel más activo del Estado en estos asuntos. Joseph Stiglitz por ejemplo señala que el buen funcionamiento de los mercados requiere políticas de regulación fiscal, fomento de la competencia, de la educación, de la transmisión de tecnología y de transparencia. Destaca asimismo que la experiencia recogida en materia de privatizaciones demuestra que la privatización sin fomento gubernamental de la competencia y sin regulación pública favorece la búsqueda de rentas -cuestión ésta en la que la empresa privada no es distinta de la estatal: lo importante es la existencia de situaciones de monopolio u oligopolio, no el tipo de derechos de propiedad (STIGLITZ, 1998). Por su parte Jagdish Bagwatti señaló recientemente la insensatez de desregular las transacciones monetarias: desregular el comercio de mercancías reporta beneficios para todas las partes, plantea

21 Este reenfoque del papel necesario de las instituciones políticas para el mejor funcionamiento de los mercados debe mucho a los aportes de North. Cf. por ejemplo North (1993).
Bagwatti, mientras que lo opuesto sucede con la desregulación de la especulación monetaria (BAGWATTI, 1998). Las recomendaciones a favor de una regulación de los movimientos especulativos de capital y la adopción de medidas que desaceleren la circulación internacional de los flujos financieros - bajo la forma de un impuesto tipo Tobin, de medidas unilaterales como las adoptadas en América Latina por los gobiernos de Chile y Colombia, u otras - ha adquirido creciente insistencia. Con el triple telón de fondo de la crisis que detonó en Asia en 1997, la bancarrota de Rusia en 1998, y la crisis brasileña de 1999, 25 ministros de finanzas de Europa y Asia se reunieron en Francfort en enero 1999 para buscar salidas a la creciente inestabilidad de la economía mundial. Con el apoyo de Japón y de Francia, el ministro de Finanzas de Alemania impulsó la creación de un sistema de control de los mercados financieros con el fin de evitar movimientos especulativos y expectativas erróneas ${ }^{22}$.

No debería verse como una contradicción lógica que los mismos economistas que hace un par de años recomendaban el desmantelamiento de las capacidades del Estado hoy recomienden con similar entusiasmo el fortalecimiento del Estado y la necesidad de ir "más allá del consenso de Washington" 23 . Se critica un tipo de gestión estatal y se recomienda otro en función de diferentes patrones de acumulación, y de otros referentes políticos.

La cuestión de la dinámica Estado/globalización debe colocarse por lo tanto en términos de la dinámica cambiante de las capacidades estatales en función de estrategias determinadas de acumulación y de articulación externa. Las capacidades estatales no existen en el vacío sino de acuerdo a estrategias específicas de desarrollo impulsadas por actores determinados, en escenarios internacionales concretos. Los ejemplos mencionados más arriba fueron escogidos intencionalmente porque corresponden a objetivos, instrumentos y estilos de acción típicos de la variante latinoamericana de macroeconomía

22 Cf. Viceconte (1999) y Hutton (1996).

23 Compárese por ejemplo el antiestatismo virulento de Burki \& Edwards (1996) con el neoestatismo de Burki et al. (1998). 
keynesiana. Los desafíos a los que debe hoy responder la gestión pública en el terreno de la economía son otros ${ }^{24}$. El desarrollo industrial del sudeste de Asia ofrece un panorama diferente en lo que toca a las modalidades de articulación entre Estado y mercado, y a las capacidades desarrolladas por el Estado ${ }^{25}$. Más aún: existe creciente consenso en explicar la crisis financiera reciente en algunos de esos países por el desmantelamiento de los mecanismos de regulación estatal que orientaron la estrategia de desarrollo hasta bien entrada la década de $1990^{26}$. Pero incluso en América Latina es posible advertir el desarrollo de nuevas capacidades estatales en función de los nuevos escenarios internacionales. Se mencionaron más arriba los mecanismos de protección frente a movimientos especulativos de capital adoptados por Chile y posteriormente por Colombia. Brasil, por su lado, demuestra mantener capacidad de manejo de instrumentos arancelarios para proteger su comercio exterior y su industria nacional del impacto de la actual crisis financiera. La ineficacia de algunos instrumentos tradicionales puede ser compensada con el manejo creativo de otros: por ejemplo, restricciones fuertes en materia de política monetaria que inhiben la implementación de políticas crediticias de promoción, pueden ser contrapesadas con una adecuada política de encaje bancario; una política eficaz de regulación de la prestación de servicios públicas tiene impacto en los ingresos reales de los usuarios y previene el rentismo a que los prestadores son proclives en situaciones de monopolio u oligopolio. Políticas de desarrollo de capital humano, de preservación dinámica del medio ambiente, de fomento de la productividad y la competitividad, están siempre abiertas a los gobiernos con creatividad y decisión política.

\section{CONSIDERACIONES FINALES}

Por encima de las variaciones registradas en

\footnotetext{
24 Vid por ejemplo Crotty (1989), Urriola (1996) y Lerda (1996).

25 Vid por ejemplo Johnson (1982), Wade (1990), Evans (1989, 1995), Tabb (1995), Hirst \& Thompson (1996).

26 Por ejemplo, el desmantelamiento de las atribuciones del Economic Planning Board en Corea desde 1994 - por recomendación de funcionarios formados en universidades estadounidenses - y el consiguiente relajamiento de la fiscalización de las operaciones de los chaeboles. Cf. Cummings (1998) y Weiss (1998, p. 53, 60-61).
}

diferentes momentos y lugares, la relación de tensión y complementación entre Estado y capital es un ingrediente permanente del capitalismo. Esta permanencia incluye momentos y situaciones de fusión del poder político y el poder del capital desde las grandes compañías comerciales y de poblamiento del siglo XVII hasta la producción industrial por grandes empresas estatales en el siglo XX, pasando por la autoridad política y militar de los terratenientes en el capitalismo agrario latinoamericano - y momentos y situaciones de separación funcional marcada. Es, además, una relación constitutivamente conflictiva. Se demanda y espera del Estado seguridad y condiciones propicias al proceso de acumulación, incluido un mínimo de integración social, y la legitimación institucional del predominio del capital. Esto implica costos. Diferentes actores tienen aproximaciones diferenciadas a los modos específicos en que el Estado debe, en cada momento, desempeñar aquellas funciones y al costo que es inevitable asumir. La cuestión central radica en compatibilizar el mínimo necesario de Estado con el máximo posible de rentabilidad del capital: algo que va más allá de consideraciones técnicas costo/beneficio y se interna en los meandros de la política. Es asimismo una cuestión que se plantea y se resuelve en función de estrategias determinadas de acumulación y desarrollo. El "Estado mínimo" no existe en abstracto sino en función de objetivos, metas y estrategias de acumulación y desarrollo. Esos objetivos, metas y estrategias definen las capacidades de gestión estatal y delimitan los alcances efectivos de su mayor o menor autonomía respecto de otros actores (empresas, organismos multilaterales, sindicatos, organizaciones sociales, etcétera).

En todas las épocas la intervención política del Estado creó las condiciones propicias para la apertura de las economías y las sociedades a la transnacionalización del capital. En los siglos XVII y siguientes el modo típico de expansión territorial del capitalismo requirió la previa preparación del terreno por expediciones militares. Los mercados de Africa, América y Asia se abrieron al capitalismo europeo a golpe de cañón. La infantería de marina contribuyó a la ocupación de América por el capitalismo estadounidense tanto como la astucia de sus banqueros. El paraguas militar con que Estados Unidos protegió a Japón, Corea y Taiwán en el periodo de la guerra 
fría, el apoyo a los procesos de reforma agraria que liquidaron en esos países el poder de los terratenientes feudales - al mismo tiempo que en Centroamérica conspiraba contra el gobierno guatemalteco que en esa misma época trataba de efectuar su propia reforma agraria - son elementos políticos que contribuyeron a la constitución de los escenarios en los cuales tomaron cuerpo las capacidades de los Estados desarrollistas de esa parte del mundo. En nuestros días la expansión del capital demanda el desmantelamiento de las estructuras regulatorias y proteccionistas del Estado desarrollista del pasado. La expresión "reformas amistosas al mercado" alude, precisamente, a la necesidad de la intervención estatal en ámbitos institucionales estratégicos para la expansión del capital.

Todos los momentos de transición de un tipo o estilo de acumulación a otro han Estado caracterizados por fuertes intervenciones del Estado en la economía y en la sociedad, promoviendo intereses de ciertos actores y marginando o subordinando a otros. La vulnerabilidad de los recién llegados fue compensada por una dinámica gestión estatal, hasta que las aguas del capital estuvieron en condiciones de fluir por los nuevos cauces. Intervencionismo y laissez-faire se combinan y conjugan en función de necesidades de acumulación y de grados de madurez de las fracciones hegemónicas del capital, no de preferencias ideológicas (GERSCHENKRON, 1968; VILAS, 1995).

¿Cuánto de la contracción de la autonomía decisoria del Estado se debe a la mayor internacionalización económica, y cuánto al triunfo político de los actores enrolados en la ideología neoliberal, y a la institucionalización de sus premisas doctrinarias bajo la forma de políticas estatales? La reducción del Estado a su función mínima de dotar de seguridad y de legitimación al capital es uno de los ingredientes más antiguos del pensamiento liberal. Adam Smith señaló sin circunloquios que el Estado fue creado "para la seguridad de la propiedad, [...] para la defensa del rico contra el pobre, o de quienes tienen alguna propiedad contra quienes carecen de ella" (SMITH, 1976 [1776], p. 674). Vale decir, el Estado como baluarte del capital y de la riqueza económica. Las formulaciones contemporáneas sobre la necesidad de que el Estado provea garantías a los derechos de propiedad son menos agresivas y más sofisticadas, e incluyen recomen- daciones respecto de la preservación del medio ambiente y el combate a la pobreza (WORLD BANK, 1997). Pero el núcleo de la cuestión sigue siendo el mismo.

Ningún proceso de acumulación funciona adecuadamente sin reglas claras y estabilidad macroeconómica. Existen unas cuantas vías para llegar a esas metas. Los escenarios de la globalización ofrecieron condiciones para que propuestas ideológicas elitistas, durante mucho tiempo rechazadas por segmentos amplios, y de hecho mayoritarios, de la población de muchos países, puedan ser presentadas como el resultado inevitable de las cosas. Afirmar que la contracción de las capacidades reguladoras y fiscalizadoras del Estado son el efecto de la globalización y no de la primacía de intereses y objetivos de actores determinados, dota al desmantelamiento de las funciones e instituciones públicas de una apariencia de neutralidad ideológica. La maximización de la rentabilidad del capital se metamorfosea como ineluctabilidad de la naturaleza. Un planteamiento de este tipo soslaya el papel estratégico que la reforma del Estado ha desempeñado en el avance del despliegue internacional del capital. Descarta, por lo tanto, la existencia de formas alternativas de articulación a la globalización, diferentes distribuciones de ganancias y pérdidas entre actores, modalidades diversas de relación entre Estado y mercado.

Señalar la funcionalidad del modo en que se ha llevado a cabo la reforma del Estado, para la expansión de la globalización económica, no debería ser visto como el recurso a un argumento de circularidad del tipo del huevo y la gallina, sino como una comprobación más de la estrecha interdependencia entre Estado y desarrollo del capital. Por sobre todo, este es un tema político: es decir, de relaciones de poder entre actores, de acceso diferenciado a recursos, de capacidad para proponer e imponer objetivos, metas, intereses. El discurso conservador predominante enmascara todo esto con el argumento del cambio técnico. La redefinición de la autonomía decisoria del Estado, la primacía de los actores más concentrados del mercado, la globalización del capital financiero, son presentados como otros tantos resultados del extraordinario cambio tecnológico experimentado en las últimas dos o tres décadas. Es una perspectiva interesante: si en el siglo XVIII la burguesía veía en el progreso técnico la llave de la redención social, el capitalismo de finales 
del siglo XX ve en el desarrollo científico y técnico la justificación de la desigualdad, el empobrecimiento y la fragmentación social. Por supuesto, la cuestión no es el progreso científico-técnico, sino la apropiación desigual de sus frutos. Es decir, una cuestión eminentemente política. El Estado reduce su autonomía respecto de ciertos actores (por ejemplo, grandes corporaciones, organismos financieros multilaterales, grandes inversionistas institucionales) al mismo tiempo que la amplía tremendamente respecto de otros: pequeñas y medias empresas, trabajadores, población de menores recursos, sindicatos...

Raramente los Estados de América Latina fueron autónomos respecto de los actores del mercado, y el presente no es la excepción. Esto no implica desconocer la existencia de estilos de acumulación de capital socialmente más inclusivos, o integradores, que los actuales. Esa dinámica integradora expresó la confluencia de tres elementos principales: la capacidad de presión de las clases medias y populares, la voluntad de algunas organizaciones políticas y agencias gubernamentales, y una dinámica económica que hacía de las demandas sociales otros tantos insumos para la acumulación de capital. El primer factor está hoy muy vulnerado, el segundo se encuentra en retirada, y el tercero entró en crisis hace ya tiempo. El propio funcionamiento de estos esquemas condujo a su progresivo agotamiento después de varias décadas de desempeño exitoso. Insistir en ellos refleja una actitud nostálgica difícilmente compatible con la capacidad de formular alternativas viables.

¿Es posible otra cosa? En caso afirmativo: ¿cuánto de eso otro es posible esperar del Estado? La primera pregunta plantea la cuestión de las alternativas a los escenarios actuales. La segunda apunta a la virtualidad del Estado como agente transformador de la economía. Ambas exigen una discusión que excede en mucho los alcances fijados para esta presentación, de por sí ya muy extensa.

Sin escabullirme de la cuestión, quisiera finalizar sin embargo regresando al señalamiento que formulé al comienzo de esta exposición. Ciertamente es posible mejorar la eficacia del gerenciamiento estatal de algunos procesos económicos y sociales. Existen experiencias de políticas públicas exitosas en materia de tributación, regulación de la prestación de bienes y servicios por empresas privatizadas, manejo de los equilibrios macroeconómicos, entre otras. Estos logros no son irrelevantes. A modo de ilustración, señalemos el involucramiento activo de agencias estatales de varios países en el aprestamiento para enfrentar la llamada "crisis informática" del año 2000. Esto no habría sido posible sin la importante aunque desigual modernización informática del aparato administrativo. También es posible incorporar nuevos paradigmas de gestión pública que superen el esquema burocrático de repetición rutinaria de procedimientos pre-establecidos, impulsando enfoques creativos y dinámicos orientados hacia la calidad. Estos ejemplos, y otros que podrían traerse a colación, se refieren básicamente a la dimensión administrativa o de gestión pública del Estado. Sin embargo, la efectividad de la modernización del aparato del Estado guarda siempre relación con los niveles de desarrollo social predominantes. De lo contrario se estará en presencia de bolsones o enclaves de modernización técnica de muy reducida eficacia y menor proyección - o que pueden incluso contribuir a una mayor polarización social.

La cuestión de las alternativas se refiere también a la otra dimensión del Estado, aquélla que involucra a la institucionalización de las relaciones de poder en la sociedad. A este respecto es conveniente recordar que todas las experiencias exitosas de transformación social y económica desde el Estado están asociadas a la capacidad de determinadas coaliciones de actores, para articular sus demandas y aspiraciones a la institucionalidad estatal. Vale decir, para convertir sus propias orientaciones de desarrollo en políticas estatales $\mathrm{y}$ en convicciones colectivas.

En el fondo, la capacidad del Estado para actuar sobre y con la sociedad, y el sentido de sus intervenciones, están estrechamente asociadas al carácter progresivo o retardatario de las motivaciones sociales que orientan su institucionalidad, y no sólo a la eficacia de sus instrumentos de gestión.

Recebido para publicação em 26 de maio de 1999. 
Carlos M. Vilas (cvilas@sfp.gov.ar) é Director Nacional de Capacitación no Instituto Nacional de la Administración Pública da República Argentina (INAP).

\section{REFERÊNCIAS BIBLIOGRÁFICAS}

ARBUCKI, T. 1997. Building a Bosnian Army. Jane's International Defense Review, p. 1315, Aug.

ARRIGHI, G. 1994. The long Twentieth Century. London : Verso.

ASENIERO, G. 1994. Estado, desarrollo y democracia en el este y sudeste de Asia. In : SAMIR, A. \& CASANOVA, P. G. (dirs.). El Estado y la política en el sur del mundo. Barcelona : Anthropos/CEIICH-UNAM.

BAGWATTI, J. 1998. The capital myth : the difference between trade in widgets and dollars. Foreign Affairs, Washington D. C., v. 77, n. 3, p. 7-12, May.

BID. 1997. Progreso económico y social de América Latina. Informe 1997 : América Latina tras una década de reformas. Washington D.C. : Banco Interamericano de Desarrollo.

BLACKBURN, R. 1998. The making of new world slavery. From the Baroque to the Modern, 1492-1800. London : Verso.

BORGES, A. G. 1994. Tendencias contemporáneas de la inversión extranjera directa. In (coord.) Nuevo orden mundial : reto para la inserción de América Latina. México : Instituto de Investigaciones Económicas/ UNAM.

BORGES, A. G. (coord.). 1994. Nuevo orden mundial : reto para la inserción de América Latina. México : Instituto de Investigaciones Económicas/UNAM.

BURSKI, S. J. \& EDWARDS, S. 1996. Dismantling the Populist State. Washington D.C. : The World Bank.

BURSKI, S. J., PERRY, G. E. et alii. 1996. Más allá del Consenso de Washington. La hora de la reforma institucional. Washington D.C. : The World Bank.

CASTELLS, M. 1996. The power of identity. Oxford : Blackwell.
CEPAL. 1997. La inversión extranjera en América Latina y el Caribe. Informe 1996. Santiago : Comisión Económica para América Latina y el Caribe/Naciones Unidas.

CROTTY, J. 1989. The limits of Keynesian macroeconomic policy in the age of the global marketplace. In : MacEWAN, A. \& TABB, W. K. (eds.). Instability and change in the World economy. New York : Monthly Review Press.

CUMMINGS, B. 1998. The Korean crisis and the end of "late development". New Left Review, n. 213, p. 43-72, Sept.-Oct.

DEFARGUES, P. M. 1997. La mondialisation. Paris : Presses Universitaires de France.

DOREMUS, P. N. et alii. 1998. The myth of the global corporation. Princeton, New Jersey : Princeton University Press.

EVANS, P. 1989. El Estado como problema y como solución. Desarrollo Económico, Buenos Aires, n. 140, p. 529-562, ene.-mar.

. 1995. Embedded autonomy. States and industrial transformation. Princeton, New Jersey : Princeton University Press.

FERRER, A. 1997. Hechos y ficciones de la globalización. Buenos Aires : Fondo de Cultura Económica.

GALBRAITH, J. K. 1990. A short history of financial euphoria. New York: Whittle.

GERSCHENKRON, A. 1968. El atraso económico en perspectiva histórica. Barcelona : Ariel.

GILL, S. 1992. The emerging world order and European change. In : MILIBAND, R. \& PANITCH, L. (eds.). New world order? The Socialist register. London : Merlin Press.

GRAHAM, B. 1995. Ex-G-Is work to give Bosnian force a fighting chance. The Washington Post, January 29, p. A7.

HARRIS, N. 1986. The end of the Third World. Newly Industrializing Countries and the 
decline of an ideology. London : I. B. Tauris.

HAYEK, F. A. 1983 [1978]. La desnacionalización del dinero. Madrid : Instituto de Economía de Mercado.

HELD, D. 1995. La democracia y el orden global. Del Estado moderno al gobierno cosmopolita. Barcelona : Paidos.

HIRST, P. \& THOMPSON, G. 1996. Globalization in question. Cambridge : Polity Press.

HOBSBAWM, E. 1990. Nations and nationalism since 1780. Cambridge : Cambridge University Press.

HORSMAN, M. \& MARSHALL, A. 1992. After the Nation State. London : Harper Collins.

HU, Y.-S. 1992. Global or Stateless corporations are national firms with international operations. California Management Review, p. 107-126, Winter.

HUTTON, W. 1996. Relaunching Western Economies. The Case for Regulating Financial Markets. Foreign Affairs, Washington D. C., v. 75 , n. 6 , p. 8-12, Dec.

IANNI, O. 1992. A sociedade global. Rio de Janeiro : Civilização Brasileira.

. 1996. A era do globalismo. Rio de Janeiro : Civilização Brasileira.

1998. O Príncipe eletrônico. Primeira Versão, Campinas, n. 78, nov.

JOHNSON, C. 1982. MITI and the Japanese miracle. Stanford : Stanford University Press.

KOLKO, J. 1988. Restructuring the world economy. New York : Pantheon Books.

LERDA, J. C. 1992. Globalización y pérdida de autonomía de las autoridades fiscales, bancarias y monetarias. Revista de la CEPAL, Santiago de Chile, n. 58, p. 63-77, abr.

LYNCH, C. 1992. For US firms war becomes a business. The Boston Globe, February 18.

NAVARRO, V. 1997. ¿Es la globalización económica y la tecnologización del trabajo la causa del paro? La importancia de lo político. Sistema, Madrid, n. 139, p. 5-32.

NORTH, D. 1998 [1990]. Instituciones, cambio institucional y desempeño económico. México : Fondo de Cultura Económica.
O'BRIEN, R. 1992. Global financial integration. The end of geography. London : Pinter.

OCDE. 1998. Accord multilatéral sur l'investissement. Le texte de négotiation de l'AMI. Paris : Direction des Affaires Financières, Fiscales et des Entreprises/OCDE.

OHMAE, K. 1990. The borderless world. New York : Harper \& Collins.

. 1995. El fin del Estado-nación. Santiago de Chile : Andrés Bello.

PINTO, A. \& KÑNAKAL, J. 1971. El sistema centro-periferia veinte años después. Santiago de Chile : CEPAL.

REICH, R. B. 1995. Democracy and megacorporations may be mutually exclusive. Los Angeles Times, May 13, p. 1.

ROMO, A. G. 1992. Bloques regionales y globalización de la economía. Comercio Exterior, Mexico, p. 379-386, mayo.

. 1994. La integración de bloques regionales en la globalización de la economía mundial. In : BORGES, A. G. (coord.). Nuevo orden mundial : reto para la inserción de América Latina. México : Instituto de Investigaciones Económicas/UNAM.

SHEPPARD, S. 1994. Foot soldiers of the new world order : the rise of the corporate military. New Left Review, n. 228, p. 128-138, Mar.Apr.

SIMMEL, G. 1978. The philosophy of money. London : Routledge \& Kegan Paul.

SMITH, Adam. 1976 [1776]. An inquiry into the nature and causes of the wealth of nations. Chicago : University of Chicago Press.

SMITH, Anthony D. 1986. The ethnic origins of nations. Oxford : Basil Blackwell.

STIGLITZ, J. 1998. Más instrumentos y metas más amplias para el desarrollo. Hacia el consenso post-Washington. Desarrollo Económico, Buenos Aires, n. 151, p. 691-722, octdic.

TABB, W. K. 1997. Globalization is an issue, the power of capital is the issue. Monthly Review, New York, v. 49, n. 2, p. 20-30, Jun.

URRIOLA, R. 1992. La paradoja de la globalización : más mercado y más regulación. In : 
(coord.). Economía latinoamericana : la globalización de los desajustes. Caracas : Nueva Sociedad.

VICECONTE, A. 1999. Impulsan el control de capitales. Clarín, Buenos Aires, 16 de enero.

VILAS, C. M. 1994a. América Latina en el "nuevo orden mundial". México : CEIICH/ UNAM.

. 1994b. Política y poder en el nuevo orden mundial. In : BORGES, A. G. (coord.). Nuevo orden mundial : reto para la inserción de América Latina. México : Instituto de Investigaciones Económicas/UNAM.

.1996. Después del ajuste : la política social entre el Estado y el mercado. In :

(coord.). Estado y políticas sociales después del ajuste. Debates y alternativas. Caracas : UNAM/Nueva Sociedad.

1997a. La reforma del Estado como cuestión política. Política y Cultura, México, n. 8, p. 147-185, primavera.

1997b. La CIA, al espionaje industrial. Siempre, México, 27 de febrero, p. 49.

1998. Gobernabilidad y globalización. Realidad Económica, Buenos Aires, n. 157, p. 6-16, jul.-ago.
1999. Seis idéias falsas sobre a globalização. Estudos de Sociologia, Araraquara, FCHL-UNESP, n. 6, p. 21-61.

VILAS, C. M. \& SILVA, O. 1976. Las empresas multinacionales. Buenos Aires : Crisis.

WADE, R. 1990. Governing the market. Princeton, New Jersey : Princeton University Press.

WADE, R. \& VENEROSO, F. 1998a. The Asian crisis : the high debt model versus the Wall Street-Treasury-IMF complex. New Left Review, n. 228, p. 3-23, Mar.-Apr.

. 1998b. The gathering world slump and the battle over capital controls. New Left Review, n. 231, p. 13-42, Sept.-Oct.

WEISS, L. 1997. Globalization and the myth of the powerless State. New Left Review, n. 225, p. 3-27, Sept.-Oct.

1998. The myth of the powerless State. Ithaca, New York : Cornell University Press.

WOOD, E. M. 1997. Back to Marx. Monthly Review, New York, v. 49, n. 2, p. 1-9, Jun.

WORLD BANK. 1997. The State in a changing world. World development report 1997. Washington D.C. : The World Bank.

\section{OUTRAS FONTES}

PRIVATE US COMPANIES TRAIN ARMIES

AROUND THE WORLD (1994). US News

and World Report, February 8, p. 28. 